\title{
Optical Coherence Tomography Guidance in Management of Acute Coronary Syndrome Caused by Plaque Erosion
}

\author{
Haibo Jia, MD, PhD; Takashi Kubo, MD, PhD; \\ Takashi Akasaka, MD, PhD; Bo Yu, MD, PhD
}

\begin{abstract}
For several decades, most physicians have believed that acute coronary syndrome (ACS) is caused by coronary thrombosis resulting from rupture of vulnerable plaque characterized by a thin fibrous cap overlying a large necrotic core and massive inflammatory cell infiltration. However, nearly one-third of ACS cases are caused by plaque erosion characterized by intact fibrous cap, less or absent necrotic core, less inflammation, and large lumen. Because of the limitations of current imaging modalities, including angiography and intravascular ultrasound, the importance of plaque erosion as a cause of acute coronary events is less well known. Optical coherence tomography (OCT) as an emerging modality with extremely high resolution is the only intravascular imaging modality available for identification of plaque erosion in vivo, which provides new insight into the mechanism of ACS. More importantly, the introduction of OCT to clinical practice enables us to differentiate the patients with ACS caused by plaque erosion from those caused by plaque rupture, thereby providing precise and personalized therapy based on the different underlying mechanisms. We systematically review the morphological characteristics of plaque erosion identified by OCT and its implications for the management of ACS.
\end{abstract}

Key Words: Acute coronary syndrome; Optical coherence tomography; Plaque erosion

A cute coronary syndrome (ACS) is a leading cause of death worldwide. ${ }^{1}$ Coronary thrombosis is believed to be the final pathway of ACS, which results primarily from plaque rupture (PR), followed by plaque erosion (PE) and calcified nodule $(\mathrm{CN})$. Previous pathological and imaging studies reported that $35 \%$ of thrombotic sudden coronary deaths and $25 \%$ of acute myocardial infarction (AMI) cases were caused by PE, 2,3 which is thus emerging as an important entity in terms of distinct morphology and tailored management of ACS. Pathologically, PE is characterized by detachment or dysfunction of endothelial cells with overlying thrombus. The introduction of optical coherence tomography (OCT) to clinical practice has enabled us to identify these mechanisms in vivo, which is not possible by any other imaging modality in patient who survive an acute coronary event.,5 Importantly, the differentiation of the mechanisms of these lesions from others may help us with more precise and personalized management decision making in the setting of ACS. This review focuses on the characteristics and clinical significance of PE assessed by OCT.

\section{PE as a Mechanism of ACS}

Coronary thrombosis is believed to be the major contributor to ACS, blocking blood flow and attributing to persistent or intermittent myocardial ischemia. In the past 2 decades, over 20 autopsy studies investigating PE as the underlying mechanisms responsible for coronary thrombosis have been conducted in different cohorts worldwide, implying the importance of $\mathrm{PE}$ as a substrate for acute coronary thrombosis in varying populations. Overall, of 1,847 cases of coronary thrombus, $73 \%$ was associated with ruptured plaque. ${ }^{6} \mathrm{PE}$ with intact fibrous cap, however, was present in $27 \%$ of cases. Although different studies have focused on different aspects and reported different findings regarding $\mathrm{PE}$, the main conclusion from these studies is that PE and PR are morphologically different in many aspects (Figure 1). PR is characterized by disrupted thin fibrous cap overlying a large necrotic core, massive macrophage infiltration, fewer smooth muscle cells, and expansive remodeling. In contrast, PE contains more fibrous tissue, intact fibrous cap, less or deep-seated necrotic core, lack of endothelial cells, less macrophage infiltration, more smooth muscle cells, and a hyaluronanrich endothelial matrix. ${ }^{7}$

The mechanism of PR has been extensively studied in humans and animals by pathology and intravascular imaging. Our understanding of the mechanism of ACS is predominantly informed by the theory of vulnerable plaque. Although the term "plaque erosion" in pathology was first proposed by van der Wal et al early in $1994,{ }^{8}$ its importance as a mechanism of ACS has been underestimated in vivo because of the lack of an imaging modality to identify

Received December 19, 2017; accepted December 20, 2017; released online January 13, 2018

Department of Cardiology, The 2nd Affiliated Hospital of Harbin Medical University, Harbin (H.J., B.Y.); The Key Laboratory of Myocardial Ischemia, Chinese Ministry of Education, Harbin (H.J., B.Y.), China; Department of Cardiovascular Medicine, Wakayama Medical University, Wakayama (T.K., T.A.), Japan

Mailing address: Bo Yu, MD, PhD, FACC, Department of Cardiology, The 2nd Affiliated Hospital of Harbin Medical University, The Key Laboratory of Myocardial Ischemia, Chinese Ministry of Education, Harbin 150086, China. E-mail: yubodr@163.com ISSN-1346-9843 All rights are reserved to the Japanese Circulation Society. For permissions, please e-mail: cj@j-circ.or.jp 


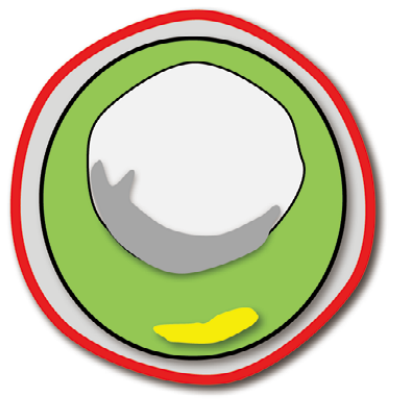

Plaque erosion

1. Intact/thick fibrous cap

2. Less/deep necrotic core

3. Platelet-rich white thrombus

4. Rich in hyaluronan

5. Amount of smooth muscle cell

6. Non-occlusive thrombus

7. Neutrophil cells involved

8. More frequent in Non-STEMI

9. Younger age

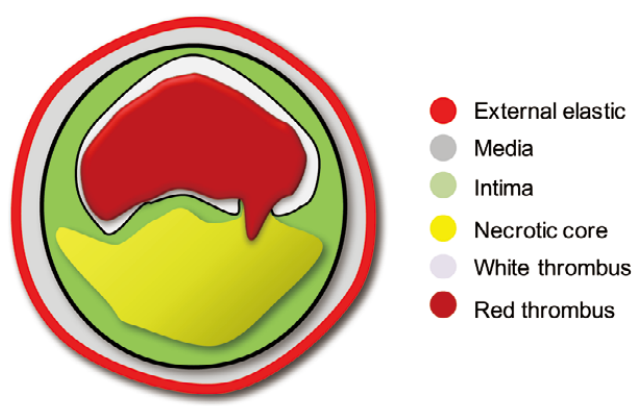

Plaque rupture

1. Ruptured/thin fibrous cap

2. Large necrotic core

3. Red blood cells-rich red thrombus

4. Lack of collagen

5. Few smooth muscle cell

6. Occlusive thrombus

7. Macrophage prominent

8. Expansive remodeling

9. More frequent in STEMI

Figure 1. Pathological features of ruptured plaque and eroded plaque. STEMI, ST-elevation myocardial infarction.

the lesion. The advent of OCT with its unprecedented resolution, making it the only imaging modality available for in vivo diagnosis of $\mathrm{PE}$, provides new insight into the mechanisms of acute coronary thrombosis. In pathology studies, PE occurred on either pathological intimal thickening or thick-cap fibroatheromas with preserved media. Typically, the endothelial cells are absent at the eroded site. The exposed intima consists predominantly of smooth muscle and proteoglycans, and in contrast to PR, PE shows minimal inflammation. ${ }^{\mathbf{8} 9}$ Interestingly, autopsy studies report that $\mathrm{PE}$ is more common in young women and men $<50$ years of age and associated with smoking, and diabetes, especially in premenopausal women. Although these findings were not consistently observed in clinical studies focusing on patients who survived acute coronary events, 4,10,11 patients with ACS caused by PE vs. PR had different characteristics, being younger and more often presenting with non-ST-segment elevated ACS. This discrepancy between histology and imaging studies may be caused by differences in study populations and definitions for identifying eroded lesions by autopsy and OCT.

\section{OCT-Defined PE}

$\mathrm{PE}$ is defined by pathology as thrombosis overlying a lesion with intact fibrous cap but detachment of endothelial cells. However, the size of an endothelial cell is less than $10 \mu \mathrm{m}$, which is under the resolution of any imaging modality, including OCT $(10-20 \mu \mathrm{m})$. However, OCT can readily differentiate $\mathrm{PR}$ from other types of lesion that lack the ruptured morphology of the culprit lesions of ACS.
Therefore, the absence of $\mathrm{PR}$ is a reliable identification of PE.

Our group first characterized the in vivo morphological features of $\mathrm{PE}$ and $\mathrm{CN}$ in patients with ACS and proposed an OCT definition of erosion. ${ }^{4}$ On OCT images, the cause of ACS is classified as PR, OCT-erosion, OCT-CN and other uncommon mechanisms (Figure 2). PR is defined as a lesion with a discontinuous fibrous cap mostly accompanied by a ruptured cavity at the site of a lipid-rich plaque, and thrombi are often found in the ruptured segment. PE is defined as a lack of fibrous cap disruption and rupture cavity because the underlying plaque type is mainly fibrous plaque. Definite OCT-erosion is defined as intact fibrous cap with thrombosis and the underlying plaque structure can be visualized. Probable OCT-erosion includes 2 types: first, intact fibrous cap with no thrombosis in and around the culprit lesion, and irregular luminal surface; second, there is thrombosis at the culprit lesion site resulting in obscuring of the underlying plaque structure, and superficial lipid pool and calcification are not found proximal or distal to the thrombus. ${ }^{4}$ There is also fibrous cap disruption and thrombosis in OCT-CN (Table). ${ }^{4}$ Among 126 lesions assessed by the proposed OCT definitions, 55 cases of PR $(43.7 \%), 39$ of erosions $(31.0 \%)$, and 10 of CNs $(7.9 \%)$ were identified. These data are consistent with the prevalence of underlying plaque morphology reported in the previous autopsy studies, which suggests the feasibility of the OCT classification for culprit lesions of ACS.6,7 Some groups have proposed different terminology for lesions with intact fibrous cap to define PE by OCT to avoid confusion with the pathological definition of PE. ${ }^{\mathbf{1 2 , 1 3}}$ 

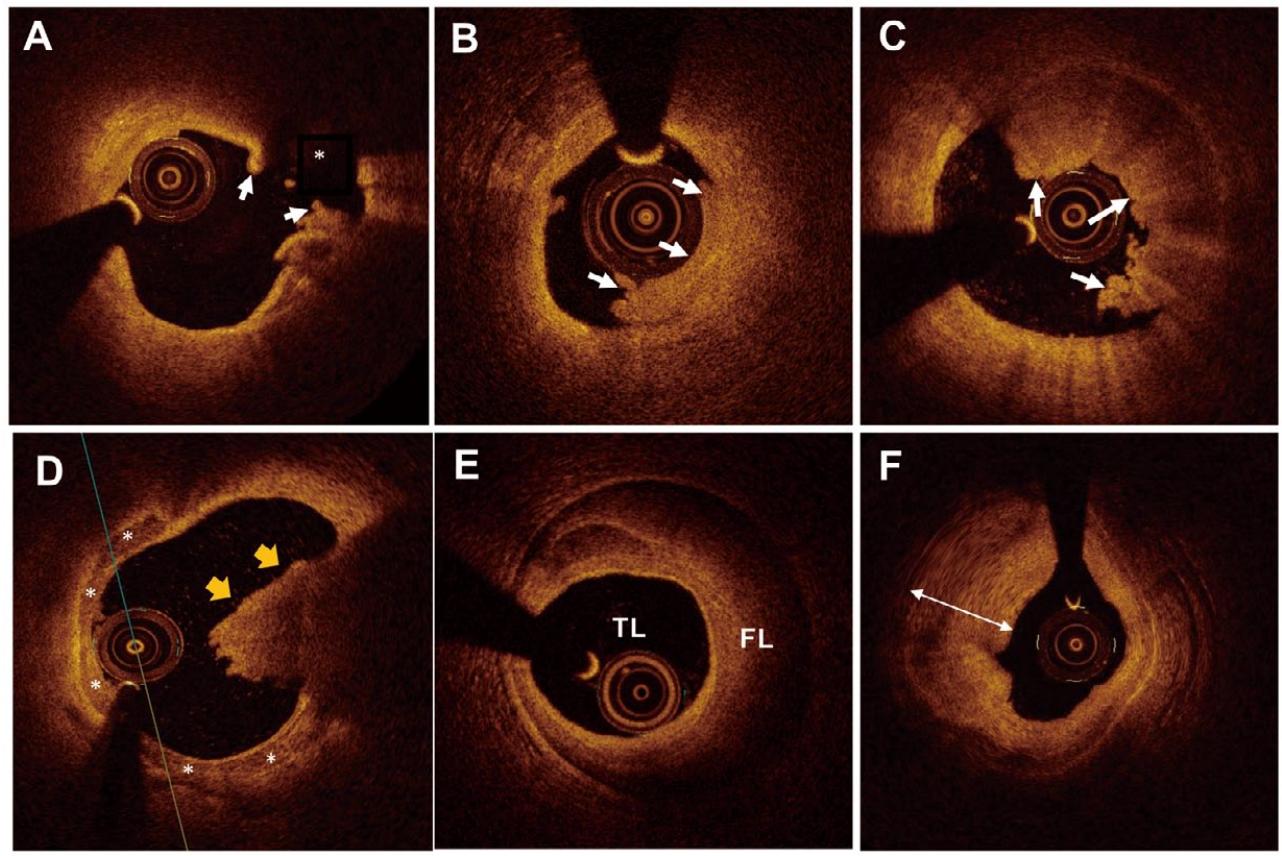

Figure 2. Representative images of culprit lesions by optical coherence tomography (OCT). (A) Plaque rupture: disrupted fibrous cap (white arrows) with presence of a cavity (asterisk). (B) Definite plaque erosion: mural thrombosis (white arrows) overlying an intact fibrous cap plaque. (C) Probable plaque erosion: presence of massive thrombus (white arrows) without superficial lipid pool and calcification immediately proximal or distal to the thrombus. (D) Calcified nodule: presence of thrombus (yellow arrows) overlying a superficial and protruding calcification (asterisk). (E) Spontaneous coronary artery dissection with hematoma (TL, true lumen; FL, false lumen). (F) Coronary spasm characterized by intimal/medial thickening (double arrow).

\begin{tabular}{ll}
\hline $\begin{array}{l}\text { Table. OCT Definitions of ACS Culprit Lesions } \\
\text { Lesion type }\end{array}$ & \multicolumn{1}{c|}{ Description } \\
Plaque erosion & $\begin{array}{l}\text { Intact fibrous cap; with or without luminal thrombosis; underlying plaque can be lipid, fibrous, or intimal thickening; } \\
\text { calcification rare }\end{array}$ \\
$\begin{array}{l}\text { Definite OCT-erosion } \\
\text { Probable OCT-erosion }\end{array}$ & $\begin{array}{l}\text { Luminal thrombus; intact fibrous cap; underlying plaque visible } \\
\text { (a) Absence of luminal thrombus; irregular luminal surface }\end{array}$ \\
& $\begin{array}{l}\text { (b) Luminal thrombus; attenuation of underlying plaque by thrombus; no superficial lipid or calcification } \\
\text { immediately proximal or distal to the site of thrombus }\end{array}$ \\
Plaque rupture & Lipid plaque with cap disruption; with or without luminal thrombus; cavity may exist \\
Calcified nodule & $\begin{array}{l}\text { Disrupted fibrous cap; protruding nodular calcification with underlying fibrocalcific plaque; luminal thrombus; } \\
\text { superficial calcium; substantive calcium proximal and/or distal to lesion }\end{array}$
\end{tabular}

ACS, acute coronary syndrome; OCT, optical coherence tomography.

However, the morphological features used in those studies to define this type of substrate by OCT are more or less same.

\section{Incidence of PE in Clinical Practice}

As previously discussed, pathology studies revealed that $25-40 \%$ of patients with sudden coronary death were attributable to PE. ${ }^{3,14}$ van der Wal et al ${ }^{8}$ reported that PE may occur in up to $40 \%$ of patients dying of fatal coronary thrombi, similarly reported by Virmani et al. ${ }^{2}$ White et al reported from postmortem studies that the incidence of PE ranged from $22 \%$ to $44 \%$ in cases of sudden cardiac death. ${ }^{15}$ Arbustini et al reported that PE was the underly- ing mechanism in $25 \%$ of patients dying of AMI. ${ }^{16}$ Most of our understanding of the prevalence of $\mathrm{PE}$ as a substrate for ACS has derived from these autopsy studies. The advent of OCT enables us to assess the prevalence of PE in the living patient in clinical practice. Kubo et al investigated PE in 30 patients with AMI using OCT, IVUS and coronary angioscopy: the incidence of PE was $23 \%$ by OCT, $3 \%$ by angioscopy, and $0 \%$ by IVUS. ${ }^{17}$ In a recent OCT study, using a different algorithm, we reported that the prevalence of PE was $31 \%$ in patients with ACS. ${ }^{4}$ Subsequently, Higuma et al reported that PE was responsible for $26.8 \%$ of cases of ST-elevated myocardial infarction (STEMI). ${ }^{10}$ Most recently, we prospectively studied the prevalence of PE in a large cohort of 405 ACS patients. Of 


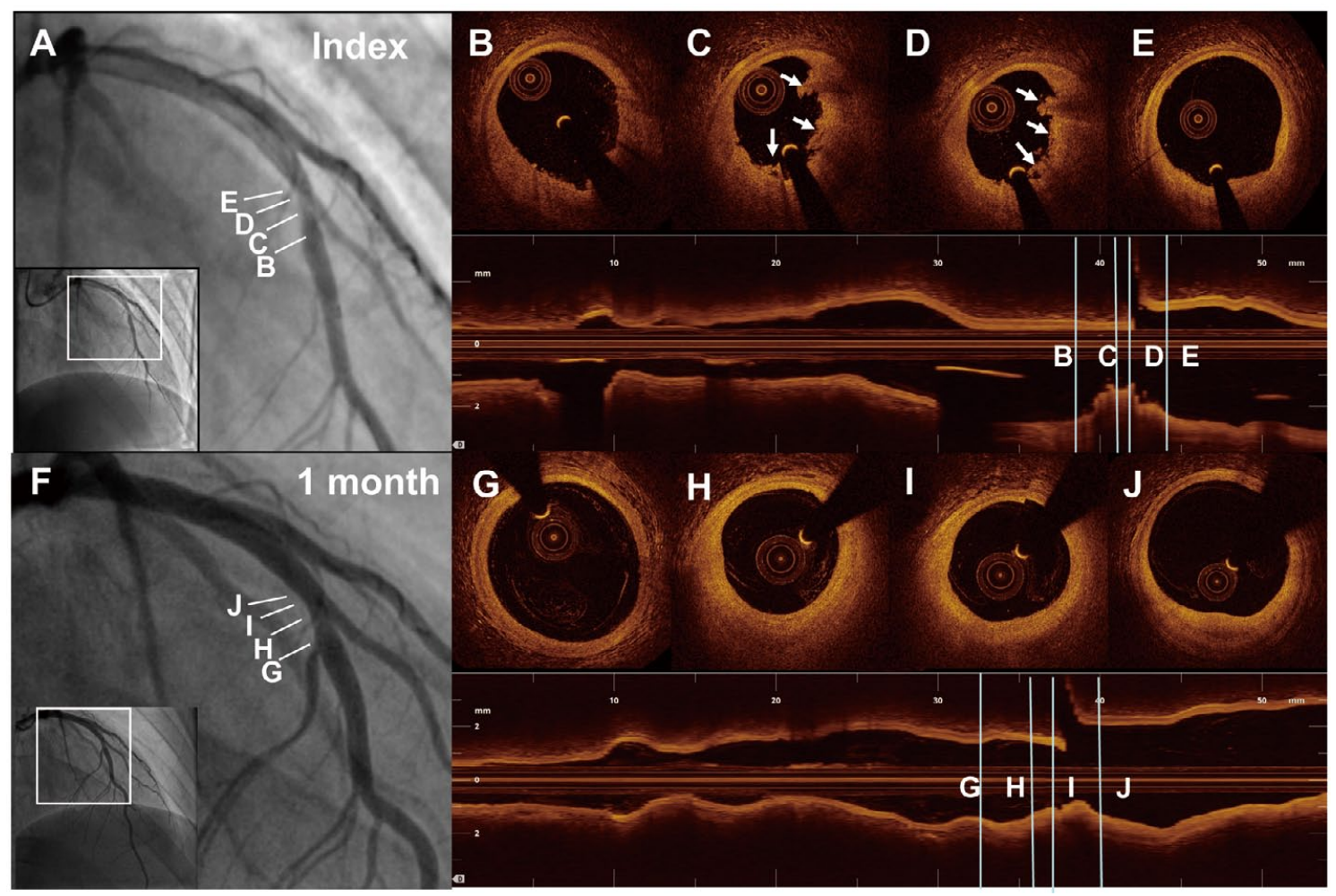

Figure 3. Representative case of ST-segment elevation myocardial infarction (STEMI) caused by plaque erosion in a 27-year-old man. Baseline angiogram (A) shows a total occluded lesion in the mid left anterior descending artery (LAD). After thrombus aspiration, residual stenosis on the angiogram (A) at the culprit site was mild (40\%). Serial optical coherence tomography (OCT) cross-sectional images from distal to proximal (B-E) of the culprit lesion indicate plaque erosion with white thrombus (arrows). After 1 month of treatment with antithrombotic agents, angiogram $(\mathbf{F})$ shows a $30 \%$ stenosis, and OCT images (G-J) show no visible thrombus overlying a fibrous plaque.

them $(97.0 \%$ STEMI), $103(25.4 \%)$ cases were caused by $\mathrm{PE}$ and $246(60.7 \%)$ by PR. ${ }^{18}$ This result was consistent with those of the previous postmortem and retrospective studies.

\section{Superiority of OCT in Diagnosing PE}

For several decades, angiography has been the golden standard for diagnosing and treating patients with ACS. However, this conventional tool has recognized limitations and is not sensitive enough to characterize intravascular plaque morphology. Angiography is unable to provide the information regarding plaque composition and frequently underestimates the true plaque burden. ${ }^{19}$ Recently, Kwon et al reported that in most cases of PE the coronary angiogram is nearly normal, which might result in misdiagnosis in an ACS patient. ${ }^{20}$

IVUS is a widely used technique to assess vascular geometry and morphology, including plaque burden, and the external elastic membrane, which are challenging for OCT in most of cases. Nonetheless, the ability to identify plaque tissue characteristics by IVUS is limited. Specifically, PE occurs superficially on the surface of the coronary artery wall. Kwon et al reported that identification of PE is challenging for IVUS because of its low resolution. ${ }^{20}$ Other previous ex vivo studies have shown that standard gray-scale IVUS may not be adequately sensitive for the detection of different plaque characteristics. ${ }^{21-24}$

Using coronary angioscopy, Kubo et al defined PE as a rough surface erosion without a disrupted fibrous cap protruding into the vessel lumen; however, most of the eroded lesions identified by OCT could not be recognized by angioscopy. ${ }^{17}$

These limitations are mostly overcome by OCT, which can provide cross-sectional intravascular imaging with approximately $10-20-\mu \mathrm{m}$ resolution, making it possible for visualize the superficial microfeatures of the coronary artery wall. ${ }^{25,26}$ Therefore, OCT is the ideal intravascular imaging tool to date that can be used to detect PE in vivo, though recognizing a single endothelial cell is still beyond the capability of OCT. Although the OCT definition of PE has not been validated by a pathology study, several autopsy reports have validated the morphological features of atherosclerotic plaque and thrombi by OCT and histology comparison. ${ }^{27-29}$ Yabushita et al examined 357 diseased coronary artery segments by OCT and histology and validated OCT's unique capacity to accurately characterize plaque structures. ${ }^{30}$ Meng et al used a rabbit atherosclerotic model to show that OCT provided an accurate assessment of intravascular thrombosis, which showed great correlation with the pathological findings. ${ }^{28}$ 


\section{Opportunities and Challenges for the Treatment of PE}

With the advent of OCT imaging for in vivo diagnosis of $\mathrm{PE}$ in patients with ACS, PE has drawn a lot of attention in catheterization laboratories in recent years. Both autopsy and clinical studies have suggested distinct pathological features and clinical characteristics of PR and PE. PR induces massive thrombus formation at the culprit site, whereas PE seems to result in less thrombus burden, preserved vascular structure, and larger vessel lumen. Interestingly, non-STEMI (NSTEMI) patients tend to be associated with PE, whereas STEMI patients tend to have PR. PE appears more frequently with a patent infarctrelated vessel with smaller infarcts by enzymatic estimation in comparison with PR. ${ }^{4,31,32} \mathrm{Hu}$ et al also reported that $\mathrm{PE}$ are more common in single- vs. multivessel disease $(67.7 \%$ vs. $30.4 \%$ ), which is different from PR. ${ }^{33}$

Additionally, several studies have confirmed the observed differences between rupture- and erosion-prone coronary plaques in the patients' demographics. For PE, smoking and female sex are significant risk factors. ${ }^{15} \mathrm{PE}$ are likely to involve younger patients, especially premenopausal women, with the major risk factor of smoking. $3,9,14,34$ Several studies have revealed the propensity of women less than 50 years old to suffer PE compared with men. , $34-38^{-38}$ Braunwald also reported a high proportion of $\mathrm{PE}$ in women younger than 50 years of age and premenopausal smokers. ${ }^{39}$

Despite the different pathophysiology and demographic characteristics of PR and PE, both are similarly treated in current clinical practice with PCI and stenting. Given the intact endothelium, the relatively preserved underlying vascular structure, and the relatively large lumen, we propose that effective antithrombotic treatment without stent implantation might be an option for patients with ACS caused by PE. Those patients could avoid stent implantation and the early and late complications related to stenting.

To test this hypothesis, we performed a prospective single-center, uncontrolled, prospective, proof-of-concept study in patients with ACS including STEMI (EROSION study):18 patients diagnosed with PE by OCT and with residual diameter stenosis $<70 \%$ on coronary angiogram were treated with antithrombotic therapy without stenting. OCT was repeated at 1 month and thrombus volume was measured. ${ }^{18}$ In total, 1 patient died of gastrointestinal bleeding, and another patient required repeat PCI. The remaining patients remained asymptomatic with obvious and meaningful decrease in thrombus volume as the primary endpoint. At 1-year follow-up, OCT demonstrated a further reduction in thrombus volume from 1 month to 12 months. A majority $(92.5 \%)$ of patients with ACS caused by $\mathrm{PE}$ and managed with aspirin and ticagrelor without stenting remained free of major adverse cardiac events (MACE) for up to 1 year (unpublished data). A representative case from the EROSION study is shown in Figure 3. This pilot study suggested that for patients with ACS caused by PE, conservative treatment with antithrombotic therapy without stenting may be an option.

Similarly, Amabile et al reported that optimal medical therapy could reduce thrombus volume and that this decrease could be gauged by OCT. ${ }^{40}$ Prati et al believe when accurate imaging is obtained and able to distinguish rupture or calcification of the culprit coronary lesion, we can compare the safety and efficacy of these alternative approaches. ${ }^{41}$ Saia et al analyzed STEMI patients (divided into intact fibrous cap and ruptured fibrous cap groups) before and after PCI in 9 months; importantly, low levels of neointimal obstruction, high rates of strut coverage, and minimal rates of late malapposition were observed in the PE group. ${ }^{42}$

\section{Outcomes in Patients With PE and PR}

PE compared with PR shows different lesion severity, plaque features and thrombus composition that may lead to different outcomes. There is greater possibility for distal embolization in PE than with PR, because of the much longer existence of thrombus, ${ }^{36}$ which is consistent with the report by Schwartz et al that there was an increase in microvascular occlusion downstream of PE compared with PR. ${ }^{38}$ White et al proposed that a residual incidence of MI and stroke was more common and might be attributed to PE. ${ }^{15}$ However, Jia et al indicated that PE was related to better myocardial perfusion than PR in STEMI patients. ${ }^{4}$ Another study of Niccoli et al suggested the prevalence of MACE was 3.7-fold higher in patients with PR compared with those with PE. ${ }^{\mathbf{2}}$

Steg et $\mathrm{a}^{\mathbf{4 3}}$ reflected on the balance of potential benefits and risks: unstented lesions may be responsible for the high risk of re-occlusion, as stenting is associated with low reocclusion rates of $2 \%$. Keeley et al found that re-occlusion rates were reduced by $57 \%$ in PCI when compared with thrombolysis. ${ }^{44}$ Brouwer et al found that re-occlusion rates after thrombolysis in STEMI were as high as $29 \%$ at 3 months after successful thrombolysis; terribly, this evolved into a cardiac mortality rate of $27 \%$ at 10 years. ${ }^{45}$ PR was associated with higher peak CK level after primary PCI than PE in a previous IVUS and angioscopy study in AMI patients. ${ }^{17}$

Higuma et al found that PE was accompanied by a lower incidence of no-reflow compared with PR, though the incidence of TIMI flow was similar. ${ }^{10}$ Time delay to reperfusion was an important cause of no-reflow, along with thrombus and age.46-50 They all shared common features of endothelial injury. Multifactorial pathogenic mechanisms are involved in the no-reflow in AMI: distal embolization, ischemic injury, reperfusion injury, and individual sensitivity. Recently, Yonetsu et al studied 318 patients with ACS (131 PE, 141 PR) who were followed for a median duration of 576 days. They found culprit lesions with an intact fibrous cap showed smaller remodeling indices by IVUS, and were associated with better long-term prognosis compared with PR. ${ }^{13}$

\section{Conclusions}

$\mathrm{PE}$ is an essential mechanism of ACS. The emergence of OCT has shed new light on the identification of PE in vivo: it has well-preserved vessel lumen, less pan-vascular vulnerability and relatively large lumen area. Patients with PE will benefit from antithrombotic therapy alone, avoiding the implantation of stents. Nevertheless, future studies are needed to validate this new therapeutic approach.

\section{Acknowledgments}

B.Y. has received research grants from the National Natural Science Foundation of China (Grant no. 81330033) and the National Key R\&D Program of China (2016YFC1301100). H.J. received a grant 
from the National Natural Science Foundation of China (Grant no. 81722025 and Grant no. 81671763).

\section{References}

1. Vedanthan R, Seligman B, Fuster V. Global perspective on acute coronary syndrome: A burden on the young and poor. Circ Res 2014; 114: 1959-1975.

2. Virmani R, Kolodgie FD, Burke AP, Farb A, Schwartz SM. Lessons from sudden coronary death: A comprehensive morphological classification scheme or atherosclerotic lesions. Arterioscler Thromb Vasc Biol 2000; 20: 1262-1275.

3. Virmani R, Burke AP, Farb A, Kolodgie FD. Pathology of the vulnerable plaque. J Am Coll Cardiol 2006; 47: C13-C18.

4. Jia H, Abtahian F, Aguirre AD, Lee S, Chia S, Lowe H, et al. In vivo diagnosis of plaque erosion and calcified nodule in patients with acute coronary syndrome by intravascular optical coherence tomography. J Am Coll Cardiol 2013; 62: 1748-1758.

5. Tearney GJ, Regar E, Akasaka T, Adriaenssens T, Barlis P, Bezerra HG, et al. Consensus standards for acquisition, measurement, and reporting of intravascular optical coherence tomography studies: A report from the International Working Group for Intravascular Optical Coherence Tomography Standardization and Validation. J Am Coll Cardiol 2012; 59: 1058-1072.

6. Falk E, Nakano M, Bentzon JF, Finn AV, Virmani R. Update on acute coronary syndromes: The pathologists' view. Eur Heart J 2013; 34: 719-728.

7. Virmani R, Kolodgie FD, Burke AP, Farb A, Schwartz SM. Lessons from sudden coronary death: A comprehensive morphological classification scheme for atherosclerotic lesions. Arterioscler Thromb Vasc Biol 2000; 20: 1262-1275.

8. van der Wal AC, Becker AE, van der Loos CM, Das PK. Site of intimal rupture or erosion of thrombosed coronary atherosclerotic plaques is characterized by an inflammatory process irrespective of the dominant plaque morphology. Circulation 1994; 89: $36-44$.

9. Farb A, Burke AP, Tang AL, Liang TY, Mannan P, Smialek J, et al. Coronary plaque erosion without rupture into a lipid core: A frequent cause of coronary thrombosis in sudden coronary death. Circulation 1996; 93: 1354-1363.

10. Higuma T, Soeda T, Abe N, Yamada M, Yokoyama H, Shibutani $\mathrm{S}$, et al. A combined optical coherence tomography and intravascular ultrasound study on plaque rupture, plaque erosion, and calcified nodule in patients with ST-segment elevation myocardial infarction: Incidence, morphologic characteristics, and outcomes after percutaneous coronary intervention. JACC Cardiovasc Interv 2015; 8: 1166-1176.

11. Saia F, Komukai K, Capodanno D, Sirbu V, Musumeci G, Boccuzzi G, et al. Eroded versus ruptured plaques at the culprit site of STEMI: In vivo pathophysiological features and response to primary PCI. JACC Cardiovasc Imaging 2015; 8: 566-575.

12. Niccoli G, Montone RA, Di Vito L, Gramegna M, Refaat H, Scalone $\mathrm{G}$, et al. Plaque rupture and intact fibrous cap assessed by optical coherence tomography portend different outcomes in patients with acute coronary syndrome. Eur Heart J 2015; 36: $1377-1384$.

13. Yonetsu T, Lee T, Murai T, Suzuki M, Matsumura A, Hashimoto $\mathrm{Y}$, et al. Plaque morphologies and the clinical prognosis of acute coronary syndrome caused by lesions with intact fibrous cap diagnosed by optical coherence tomography. Int J Cardiol 2016; 203: $766-774$.

14. Burke AP, Farb A, Malcom GT, Liang Y, Smialek J, Virmani R. Effect of risk factors on the mechanism of acute thrombosis and sudden coronary death in women. Circulation 1998; 97: $2110-2116$

15. White SJ, Newby AC, Johnson TW. Endothelial erosion of plaques as a substrate for coronary thrombosis. Thromb Haemost 2016; 115: 509-519.

16. Arbustini E, Dal Bello B, Morbini P, Burke AP, Bocciarelli M, Specchia G, et al. Plaque erosion is a major substrate for coronary thrombosis in acute myocardial infarction. Heart 1999; 82: $269-272$.

17. Kubo T, Imanishi T, Takarada S, Kuroi A, Ueno S, Yamano T, et al. Assessment of culprit lesion morphology in acute myocardial infarction: Ability of optical coherence tomography compared with intravascular ultrasound and coronary angioscopy. $J$ Am Coll Cardiol 2007; 50: 933-939.

18. Jia H, Dai J, Hou J, Xing L, Ma L, Liu H, et al. Effective anti-thrombotic therapy without stenting: Intravascular optical coherence tomography-based management in plaque erosion (the
EROSION study). Eur Heart J 2017; 38: 792-800

19. Mintz GS, Painter JA, Pichard AD, Kent KM, Satler LF, Popma $\mathrm{JJ}$, et al. Atherosclerosis in angiographically "normal" coronary artery reference segments: An intravascular ultrasound study with clinical correlations. J Am Coll Cardiol 1995; 25: 1479-1485.

20. Kwon JE, Lee WS, Mintz GS, Hong YJ, Lee SY, Kim KS, et al. Multimodality intravascular imaging assessment of plaque erosion versus plaque rupture in patients with acute coronary syndrome. Korean Circ J 2016; 46: 499-506.

21. Prati F, Arbustini E, Labellarte A, Dal Bello B, Sommariva L, Mallus MT, et al. Correlation between high frequency intravascular ultrasound and histomorphology in human coronary arteries. Heart 2001; 85: 567-570.

22. Palmer ND, Northridge D, Lessells A, McDicken WN, Fox KA. In vitro analysis of coronary atheromatous lesions by intravascular ultrasound; reproducibility and histological correlation of lesion morphology. Eur Heart J 1999; 20: 1701-1706.

23. Patwari P, Weissman NJ, Boppart SA, Jesser C, Stamper D, Fujimoto JG, et al. Assessment of coronary plaque with optical coherence tomography and high-frequency ultrasound. Am $J$ Cardiol 2000; 85: 641-644.

24. Kume T, Akasaka T, Kawamoto T, Watanabe N, Toyota E, Neishi Y, et al. Assessment of coronary arterial plaque by optical coherence tomography. Am J Cardiol 2006; 97: 1172-1175.

25. Di Vito L, Yoon JH, Kato K, Yonetsu T, Vergallo R, Costa M, et al. Comprehensive overview of definitions for optical coherence tomography-based plaque and stent analyses. Coron Artery Dis 2014; 25: 172-185.

26. Prati F, Regar E, Mintz GS, Arbustini E, Di Mario C, Jang IK, et al. Expert review document on methodology, terminology, and clinical applications of optical coherence tomography: Physical principles, methodology of image acquisition, and clinical application for assessment of coronary arteries and atherosclerosis. Eur Heart J 2010; 31: 401-415.

27. Yabushita H, Bouma BE, Houser SL, Aretz HT, Jang IK, Schlendorf KH, et al. Characterization of human atherosclerosis by optical coherence tomography. Circulation 2002; 106: $1640-$ 1645 .

28. Meng L, Lv B, Zhang S, Yv B. In vivo optical coherence tomography of experimental thrombosis in a rabbit carotid model. Heart 2008; 94: 777-780.

29. Otsuka F, Joner M, Prati F, Virmani R, Narula J. Clinical classification of plaque morphology in coronary disease. Nat Rev Cardiol 2014; 11: 379-389.

30. Yabushita H. Characterization of human atherosclerosis by optical coherence tomography. Circulation 2002; 106: 1640-1645.

31. Stone GW, Narula J. Emergence of plaque erosion as an important clinical entity. JACC Cardiovasc Imaging 2015; 8: 623-625.

32. Ino Y, Kubo T, Tanaka A, Kuroi A, Tsujioka H, Ikejima H, et al. Difference of culprit lesion morphologies between ST-segment elevation myocardial infarction and non-ST-segment elevation acute coronary syndrome: An optical coherence tomography study. JACC Cardiovasc Interv 2011; 4: 76-82.

33. Hu S, Zhu Y, Zhang Y, Dai J, Li L, Dauerman H, et al. Management and outcome of patients with acute coronary syndrome caused by plaque rupture versus plaque erosion: An intravascular optical coherence tomography study. J Am Heart Assoc 2017; 6: e004730.

34. Burke AP, Farb A, Pestaner J, Malcom GT, Zieske A, Kutys R, et al. Traditional risk factors and the incidence of sudden coronary death with and without coronary thrombosis in blacks. Circulation 2002; 105: 419-424.

35. Kubo T, Tanaka A, Kitabata H, Ino Y, Tanimoto T, Akasaka T. Application of optical coherence tomography in percutaneous coronary intervention. Circ J 2012; 76: 2076-2083.

36. Kramer MC, Rittersma SZ, de Winter RJ, Ladich ER, Fowler DR, Liang YH, et al. Relationship of thrombus healing to underlying plaque morphology in sudden coronary death. $\mathrm{J} \mathrm{Am} \mathrm{Coll}$ Cardiol 2010; 55: 122-132.

37. Tavora F, Cresswell N, Li L, Ripple M, Fowler D, Burke A. Sudden coronary death caused by pathologic intimal thickening without atheromatous plaque formation. Cardiovasc Pathol 2011; 20: $51-57$.

38. Schwartz RS, Burke A, Farb A, Kaye D, Lesser JR, Henry TD, et al. Microemboli and microvascular obstruction in acute coronary thrombosis and sudden coronary death: Relation to epicardial plaque histopathology. J Am Coll Cardiol 2009; 54: 2167-2173.

39. Braunwald E. Coronary plaque erosion. JACC Cardiovasc Imaging 2013; 6: $288-289$.

40. Amabile N, Hammas S, Fradi S, Souteyrand G, Veugeois A, 
Belle L, et al. Intra-coronary thrombus evolution during acute coronary syndrome: Regression assessment by serial optical coherence tomography analyses. Eur Heart J Cardiovasc Imaging 2014; 16: 433-440.

41. Prati F, Uemura S, Souteyrand G, Virmani R, Motreff P, Di Vito L, et al. OCT-based diagnosis and management of STEMI associated with intact fibrous cap. JACC Cardiovasc Imaging 2013; 6: $283-287$.

42. Saia F, Komukai K, Capodanno D, Sirbu V, Musumeci G, Boccuzzi G, et al. Eroded versus ruptured plaques at the culprit site of STEMI. JACC Cardiovasc Imaging 2015; 8: 566-575.

43. Steg PG, van't Hof A, Hamm CW, Clemmensen P, Lapostolle $\mathrm{F}$, Coste $\mathrm{P}$, et al. Bivalirudin started during emergency transport for primary PCI. $N$ Engl J Med 2013; 369: 2207-2217.

44. Keeley EC, Boura JA, Grines CL. Primary angioplasty versus intravenous thrombolytic therapy for acute myocardial infarction: A quantitative review of 23 randomised trials. Lancet 2003; 361: $13-20$

45. Brouwer MA, Kievit PC, Dieker HJ, Veen G, Karreman AJ, Verheugt FW. Sustained coronary patency after fibrinolytic therapy as independent predictor of 10 -year cardiac survival:
Observations from the Antithrombotics in the Prevention of Reocclusion in COronary Thrombolysis (APRICOT) trial. Am Heart J 2008; 155: 1039-1046.

46. Vancraeynest D, Pasquet A, Roelants V, Gerber BL, Vanoverschelde JL. Imaging the vulnerable plaque. $J$ Am Coll Cardiol 2011; 57: 1961-1979.

47. Jang IK, Bouma BE, Kang DH, Park SJ, Park SW, Seung KB, et al. Visualization of coronary atherosclerotic plaques in patients using optical coherence tomography: Comparison with intravascular ultrasound. J Am Coll Cardiol 2002; 39: 604-609.

48. Toda N. Age-related changes in endothelial function and blood flow regulation. Pharmacol Ther 2012; 133: 159-176.

49. Harrison RW, Aggarwal A, Ou FS, Klein LW, Rumsfeld JS, Roe MT, et al. Incidence and outcomes of no-reflow phenomenon during percutaneous coronary intervention among patients with acute myocardial infarction. Am J Cardiol 2013; 111: $178-184$.

50. Falk E. Plaque rupture with severe pre-existing stenosis precipitating coronary thrombosis: Characteristics of coronary atherosclerotic plaques underlying fatal occlusive thrombi. Br Heart $J$ 1983; 50: $127-134$ 